\title{
ESTUDO SOCIOAMBIENTAL DA BACIA DO RIO PARDO: IRRIGAÇÃO, MONOCULTURAS E CRISE HÍDRICA - Relatório de Pesquisa
}

Joaci de Sousa Cunha (CEAS; UCSal)

Gilca Garcia de Oliveira (UFBA)

Maicon Leopoldino de Andrade (CEAS)

Informações do artigo

Recebido em 08/05/2019

Aceito em 10/05/2019

doi>: https://doi.org/10.25247/2447-861X.2019.n246.p227-247

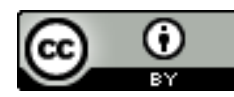

Esta obra está licenciada com uma Licença Creative

Commons Atribuição 4.0 Internacional.

Como ser citado (modelo ABNT)

CUNHA, Joaci de S.; OLIVEIRA, Gilca Garcia de;

ANDRADE, Maicon Leopoldino de. Estudo

socioambiental da bacia do Rio Pardo: irrigação,

monoculturas e crise hídrica - Relatório de Pesquisa.

Cadernos do CEAS: Revista Crítica de Humanidades,

Salvador, n. 246, jan./abr., p. 227-247, 2019. DOI: https://doi.org/10.25247/2447-861X.2019.n246.p227-247

\begin{abstract}
Resumo
Resultado de pesquisa realizada pelo Centro de Estudos e Ação Social, o presente relatório expõe, de forma direta, sem maiores análises, os resultados da investigação realizada por seus autores a respeito da problemática socioambiental na bacia hidrográfica do rio Pardo, especialmente em suas porções média, no sudoeste da Bahia, e alta, no norte de Minas Gerais.
\end{abstract}

De Porto de Santa Cruz, em Cândido Sales, até desaguar em Canavieiras, o rio Pardo percorre $345 \mathrm{~km}$ em terras baianas, do seu trajeto total de $565 \mathrm{~km}$. É verdade que, a cada período, com menos água. Não por causa exclusiva da redução das chuvas. Mas, porque agora suas águas têm dono, ou será que poderíamos dizer expropriadores?... 


\section{Introdução}

Resultado de pesquisa realizada pelo Centro de Estudos e Ação Social, o presente relatório expõe, de forma direta, sem maiores análises, os resultados da investigação realizada por seus autores a respeito da problemática socioambiental na bacia hidrográfica do rio Pardo, especialmente em suas porções média, no sudoeste da Bahia, e alta, no norte de Minas Gerais.

De Porto de Santa Cruz, em Cândido Sales, até desaguar em Canavieiras, o rio Pardo percorre $345 \mathrm{~km}$ em terras baianas, do seu trajeto total de $565 \mathrm{~km}$. É verdade que, a cada período, com menos água. Não por causa exclusiva da redução das chuvas. Mas, porque agora suas águas têm dono, ou será que poderíamos dizer expropriadores?

De fato, as outorgas da ANA para a Bacia Hidrográfica do Rio Pardo (BHRP) revelam que $89,5 \%$ do volume das águas outorgadas é utilizado para irrigação e apenas $8,7 \%$ para abastecimento humano e 0,5\% para esgotamento sanitário. Talvez, isso explique porque Cândido Sales, Encruzilhada e Itambé têm enfrentado forte crise de abastecimento nos últimos anos.

Em Minas e Bahia, são 37 municípios na BHRP, sendo 13 mineiros e 24 baianos, com uma população superior a um milhão de habitantes (em 2010, eram 911.708), estando 83,2\% deles no estado da Bahia e 16,7\% no estado de Minas Gerais (CENSO DEMOGRÁFICO/IBGE, 2010).

Quadro 1-Relação de municípios integrantes da BHRP por Estado

\begin{tabular}{|l|l|}
\hline \multicolumn{1}{|c|}{ BAHIA } & \multicolumn{1}{|c|}{ MINAS GERAIS } \\
\hline Cândido Sales, Encruzilhada, Ribeirão do Largo, & Rio Pardo de Minas, Montezuma, Santo Antônio do \\
Macarani, Itambé, Vitória da Conquista, Barra do & Retiro, Vargem Grande do Rio Pardo, São João do \\
Choça, Caatiba, Belo Campo, Itapetinga, Itarantim, & Paraíso, Indaiabira, Taiobeiras, Santa Cruz de \\
Pau Brasil, Camacã, Potiraguá, Mascote, Maiquinique, & Salinas, Berizal, Águas Vermelhas, Divisa Alegre, \\
Santa Luzia, Planalto, Nova Cannaã, Tremedal, Piripá, & Ninheira e Curral de Dentro. \\
Poções e Canavieiras. & \\
\hline
\end{tabular}

Fonte: (IBGE, 2010)

A partir do encontro "Os (des)caminhos da Bacia do Rio Pardo e seus afluentes: água hoje e amanhã" para o trecho baiano, organizado pelo Fórum de Entidades e Movimentos Sociais do Sudoeste da Bahia, em Vitória da Conquista (dez. 2016), foi que se adotou a forma de atuar em defesa do rio Pardo a partir das microbacias dos seus afluentes, além das questões gerais de sua calha central. Nesse encontro, o diagnóstico dos problemas foi sintetizado no quadro abaixo. 
Quadro 2 - Problemas identificados

\begin{tabular}{|c|c|c|c|c|c|}
\hline Grupo 1 & Grupo 2 & Grupo 3 & Grupo 4 & Grupo 5 & Grupo6 \\
\hline $\begin{array}{l}\text { Desmatamento } \\
\text { em topos e pé de } \\
\text { morros e de } \\
\text { nascentes }\end{array}$ & $\begin{array}{l}\text { Nascentes, falta } \\
\text { de consciência da } \\
\text { importância da } \\
\text { sua preservação } \\
\text { e proteção } \\
\text { (geral) }\end{array}$ & $\begin{array}{l}\text { Desmatamento } \\
\text { da mata ciliar }\end{array}$ & $\begin{array}{l}\text { A morte das } \\
\text { nascentes }\end{array}$ & Mata ciliares & $\begin{array}{l}\text { Nascentes } \\
\text { desprotegidas e } \\
\text { degradadas } \\
\text { (morrendo); } \\
\text { Assoreamento das } \\
\text { nascentes, dos leitos } \\
\text { dos e afluentes }\end{array}$ \\
\hline $\begin{array}{l}\text { Esgoto sem } \\
\text { tratamento }\end{array}$ & $\begin{array}{l}\text { Esgoto sem } \\
\text { tratamento }\end{array}$ & $\begin{array}{l}\text { Esgoto sem } \\
\text { tratamento }\end{array}$ & $\begin{array}{l}\text { Esgoto sem } \\
\text { tratamento }\end{array}$ & & \\
\hline \multirow[t]{2}{*}{$\begin{array}{l}\text { Agropecuária } \\
\text { extensiva }\end{array}$} & & $\begin{array}{l}\text { Monocultura } \\
\text { (eucalipto e café) }\end{array}$ & & $\begin{array}{l}\text { Monocultura } \\
\text { (eucalipto e } \\
\text { café); Pecuária } \\
\text { extensiva }\end{array}$ & \\
\hline & $\begin{array}{l}\text { Outros resíduos } \\
\text { jogados nos rios }\end{array}$ & Agrotóxico & & Agrotóxico & \\
\hline Irrigação & Irrigação & $\begin{array}{l}\text { Uso ilegal das } \\
\text { águas: irrigação }\end{array}$ & & & \\
\hline $\begin{array}{l}\text { Lixões a céu } \\
\text { aberto }\end{array}$ & $\begin{array}{l}\text { Lixões a céu } \\
\text { aberto; Lixo } \\
\text { doméstico e da } \\
\text { produção }\end{array}$ & & & Lixo & \\
\hline Mineração & & & & Mineração & \\
\hline \multirow[t]{3}{*}{ Solo degradado } & & & & & Áreas degradadas \\
\hline & & $\begin{array}{l}\text { Uso ilegal das } \\
\text { águas: pequenas } \\
\text { barragens }\end{array}$ & & Barragens & \\
\hline & & Curtumes & & & \\
\hline \multicolumn{6}{|l|}{ Queimadas } \\
\hline \multicolumn{6}{|l|}{$\begin{array}{l}\text { Indústria de } \\
\text { cerâmica }\end{array}$} \\
\hline \multicolumn{6}{|l|}{$\begin{array}{l}\text { Descaso do Poder } \\
\text { Público }\end{array}$} \\
\hline \multicolumn{6}{|l|}{$\begin{array}{l}\text { Ausência de } \\
\text { fiscalização }\end{array}$} \\
\hline & $\begin{array}{l}\text { Quase morte dos } \\
\text { Rios do Vigário, } \\
\text { Riacho de Areia, } \\
\text { Rio Novo e Rio } \\
\text { das Pombas }\end{array}$ & & & & \\
\hline & $\begin{array}{l}\text { Valetamento, } \\
\text { drenagem }\end{array}$ & & & & \\
\hline & & & & & $\begin{array}{l}\text { Perda e luta para } \\
\text { retomada dos } \\
\text { territórios }\end{array}$ \\
\hline & & & & & $\begin{array}{l}\text { Não reconhecimento } \\
\text { dos produtos, } \\
\text { organização } \\
\text { produtiva e acesso a } \\
\text { mercados }\end{array}$ \\
\hline
\end{tabular}

Fonte: Relatório Ceas do Encontro "Os (des)caminhos da Bacia do Rio Pardo e seus afluentes: água hoje e amanhã"

Esse diagnóstico já apontava para 'os caminhos e (des)caminhos do rio Pardo'. O $1^{\circ} \mathrm{e}$ - $3^{\circ}$ elemento de risco apresentados no Encontro dão conta da questão central, o desmatamento, o avanço de monocultivos e da pecuária extensiva. 


\section{Desmatamento e água para os monocultivos}

Desmatamento, ausência de áreas de proteção permanente, ou seja, a exploração exacerbada dos rios vai ser identificada como o maior problema. ${ }^{1}$ Infelizmente, a situação do rio Pardo não é diferente de outros rios, conforme os dados de desmatamento levantados pela ONG SOS Mata Atlântica.

Para o intervalo de 2000 e 2014, no trecho baiano do Rio Pardo, os quatro municípios que lideram a lista de maior área desmatada são: Cândido Sales, Encruzilhada, Vitória da Conquista e Canavieiras (Tabela 1).

Tabela 1- Municípios que mais desmataram, em ha, Bahia, 2000 a 2014

\begin{tabular}{|c|c|c|c|c|c|c|c|}
\hline & Município & $\begin{array}{c}\text { Área } \\
\text { Município } \\
\text { (ha) }\end{array}$ & $\begin{array}{c}\text { Área } \\
\text { Município } \\
\text { Lei MA (ha) }\end{array}$ & $\begin{array}{c}\text { \% Município } \\
\text { na Lei MA }\end{array}$ & $\begin{array}{c}\text { Decremento } \\
\text { de mata } \\
2014-2015\end{array}$ & $\begin{array}{c}\text { Vegetação } \\
\text { natural }\end{array}$ & $\begin{array}{c}\% \\
\text { Vegetação } \\
\text { natural }\end{array}$ \\
\hline $1^{\circ}$ & Cândido Sales & 162.316 & 162.099 & $99,9 \%$ & 5.676 & 9.223 & $5,7 \%$ \\
\hline $2^{\circ}$ & Encruzilhada & $204 \cdot 313$ & $204 \cdot 313$ & $100,0 \%$ & $5 \cdot 350$ & 13.146 & $6,4 \%$ \\
\hline $3^{\circ}$ & $\begin{array}{l}\text { Vitória da } \\
\text { Conquista }\end{array}$ & $319 \cdot 544$ & 278.732 & $87,2 \%$ & 4.610 & 15.766 & $5,7 \%$ \\
\hline $4^{\circ}$ & Canavieiras & 137.503 & 137.503 & $100,0 \%$ & 3.541 & 24.666 & $17,9 \%$ \\
\hline $5^{\circ}$ & Andaraí & 189.542 & 183.289 & $96,7 \%$ & 3.149 & 74.121 & $40,4 \%$ \\
\hline $6^{\circ}$ & Belmonte & 201.098 & 201.098 & $100,0 \%$ & 2.523 & 33.358 & $16,6 \%$ \\
\hline $7^{\circ}$ & Guaratinga & 232.401 & 232.401 & $100,0 \%$ & 2.339 & 33.386 & $14,4 \%$ \\
\hline 80 & Itamaraju & 237.092 & 237.092 & $100,0 \%$ & 2.050 & 45.409 & $19,2 \%$ \\
\hline $9^{\circ}$ & $\begin{array}{l}\text { Bom Jesus da } \\
\text { Lapa }\end{array}$ & 400.105 & 169.383 & $42,3 \%$ & 1.895 & 15.283 & $9,0 \%$ \\
\hline $10^{\circ}$ & Baianópolis & 336.990 & 81.246 & $24,1 \%$ & 1.712 & 23.003 & $28,3 \%$ \\
\hline
\end{tabular}

Fonte: https://www.sosma.org.br/wp-content/uploads/2016/12/Atlas-munic\%C3\%ADpios-SOS-Bahia.pdf

Em Minas Gerais, na Bacia do Rio Pardo, Curral de Dentro (10), Águas Vermelhas $\left(3^{\circ}\right)$, São João do Paraíso $\left(6^{\circ}\right)$ e Ninheira $\left(8^{\circ}\right)$ são os municípios que mais desmataram nesse período, ampliando a perda da biodiversidade, a erosão e o assoreamento, interferindo no ciclo da água.

Tabela 2 - Municípios que mais desmataram, em ha, Minas Gerais, 2014 a 2015, em hectares

\begin{tabular}{llrrrr}
\hline & Município & $\begin{array}{c}\text { Área Município } \\
\text { (ha) }\end{array}$ & $\begin{array}{c}\text { Área Município na } \\
\text { Lei MA (ha) }\end{array}$ & $\begin{array}{c}\text { \% Município na } \\
\text { Lei MA }\end{array}$ & $\begin{array}{c}\text { Decremento de } \\
\text { mata 2014-2015 }\end{array}$ \\
\hline $1^{\circ}$ & $\begin{array}{l}\text { Curral de } \\
\text { Dentro }\end{array}$ & 56.826 & 46.457 & $81,8 \%$ & 492 \\
$2^{\circ}$ & Jequitinhonha & 351.422 & 351.422 & $100,0 \%$ & 370 \\
$3^{\circ}$ & $\begin{array}{l}\text { Águas } \\
\text { Vermelhas }\end{array}$ & 125.928 & 125.928 & $100,0 \%$ & 338 \\
\hline
\end{tabular}

1 Filmagem realizada por drone, em setembro de 2017, disponibilizada pelo vereador de Candido Sales, Dirciano Santana. Código Florestal Brasileiro - Lei no. 12.651/2012, define no seu artigo $4^{\circ}$ que a Área de Preservaçao Permanente (APP) de um Rio varia de 30 a $500 \mathrm{~m}$ a partir da margem, variando de acordo com a largura do Rio. 


\begin{tabular}{|c|c|c|c|c|c|}
\hline $4^{\circ}$ & Gameleiras & 173.320 & 70.596 & $40,7 \%$ & 325 \\
\hline $5^{\circ}$ & Itinga & 164.962 & 164.962 & $100,0 \%$ & 298 \\
\hline $6^{\circ}$ & $\begin{array}{l}\text { São João do } \\
\text { Paraíso }\end{array}$ & $192.55^{8}$ & 190.721 & $99,0 \%$ & 279 \\
\hline $7^{\circ}$ & Mariana & 119.421 & $119 \cdot 421$ & $100,0 \%$ & 258 \\
\hline $8^{\circ}$ & Ninheira & 110.819 & 110.819 & $100,0 \%$ & 215 \\
\hline $9^{\circ}$ & Novo Cruzeiro & 170.298 & 170.298 & $100,0 \%$ & 215 \\
\hline $10^{\circ}$ & Minas Novas & 181.240 & 33.627 & $18,6 \%$ & 212 \\
\hline
\end{tabular}

Fonte:https://www.sosma.org.br/wp-content/uploads/2016/12/Atlas-munic\%C3\%ADpios-SOS-MinasGerais.pdf

Os dados de outorgas da ANA reforçam essa realidade (Tabela 3). Na Bacia do Rio Pardo são 57 outorgas em Minas Gerais, com 41,5\% do volume total autorizado, e 54 da Bahia, com 58,5\% do volume total, resultando em 111 outorgas. Destas, 12 registros são de "uso não consuntivo" (uso que não retira a água do rio), 95 pontos de captação e quatro pontos de lançamento.

A situação crítica vivenciada pelo Rio Pardo pode ser ouvida nos depoimentos das pessoas e observada pela baixa vazão do Rio, pelos municípios com desabastecimento, pelas outorgas com seus usos sem controle estatal, por pequenos produtores e ribeirinhos com grandes desafios para garantir a produção e a reprodução social de suas famílias.

Neste cenário, tem-se que, praticamente $\mathbf{9 0 \%}$ do uso das águas do Rio Pardo, em outorgas, é para irrigação (Gráfico 1). São 29 outorgas para o cultivo de café irrigado, num total de $46.728 .818 \mathrm{~m}^{3} / a n o$ que representam $64,5 \%$ de toda a água. Quatro municípios irrigantes consomem 75,7\% da água, contabilizada via outorgas da ANA, na Bacia do Rio Pardo, que são: Encruzilhada, 28,3\%; Águas Vermelhas, 23,6\%; Cândido Sales, 12,7\% e Ninheira, $11,1 \%{ }^{2}$ Neste cenário, tem-se que, praticamente $90 \%$ do uso das águas do Rio Pardo, em outorgas, é para irrigação.

\footnotetext{
2 ANA - Agência Nacional de Águas, disponível em http://www3.ana.gov.br/portal/ANA/regulacao/principais-
} servicos/outorgas-emitidas, acesso em 06/03/2018. 
Gráfico 1

PERCENTUAIS DE VOLUME ANUAL DE USO DE ÁGUA POR ATIVIDADE, BACIA DO RIO PARDO

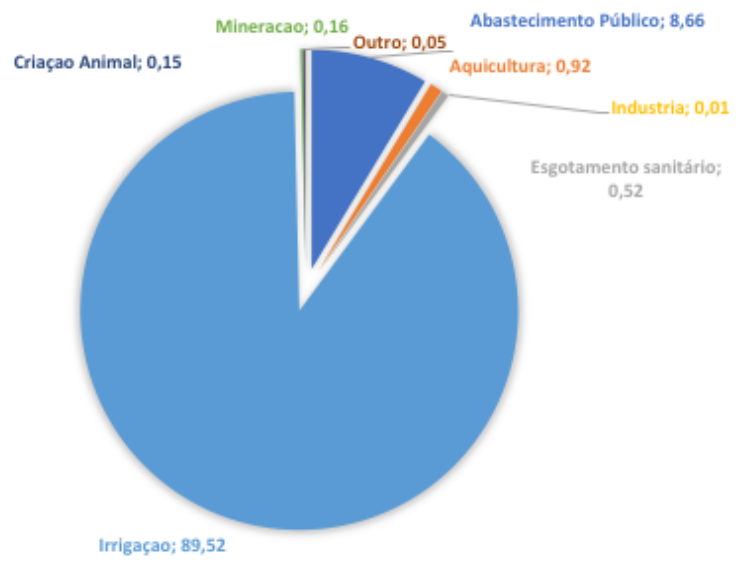

Na Bahia, são 38 outorgas para irrigação em nome de 28 irrigantes, controlando 36.710.006 m³/ano, enquanto que, para o abastecimento público de seis municípios, com 37.837 domicílios com rede geral de distribuição, ${ }^{3}$ são 5.323.237 m³/ano. Ou seja, a irrigação usa 7,0 vezes mais água que o consumo domiciliar. Tem-se em Encruzilhada, um único irrigante, Antonio Carlos Brito, com seis outorgas, num total de 4.179.383 m³/ano, Luiz Augusto Pereira Monguillod e Outros com quatro outorgas totalizando um volume de 4.584.66o m³/ano, Marcos Lacerda com três num montante de 1.747.140 m³/ano. ${ }^{4}$

Em Minas Gerais, são 35 outorgas para 32 irrigantes, controlando 28.094.562 m³/ano, enquanto que, para o abastecimento público de três municípios, com 5.670 domicílios atendidos pela rede de distribuição, são $942.076 \mathrm{~m} 3 / \mathrm{ano}$, ou seja, 29,8 vezes menos que apenas 32 agonegociantes, a exemplo de Nilo Coelho e outros, em Ninheira, com três outorgas que totalizam 7.881.470 m³/ano, e Mauro Eurípedes Rocha Mendes, em Águas Vermelhas, com $3.736 .240 \mathrm{~m}^{3} / \mathrm{ano}$, em duas.

De acordo com os STRs de Rio Pardo e Indaiabira, há uma concentração de 4 barramentos neste último município, que usariam água do Rio Pardo para irrigação, embora não constem no cadastro da ANA. Os responsáveis seriam: Ronaldo Pena (café), Natalício

3 Municípios que tem abastecimento humano a partir das águas do Rio Pardo e com captação outorgada pela ANA.

4 ANA - Agência Nacional de Águas, disponível em http://www3.ana.gov.br/portal/ANA/regulacao/principaisservicos/outorgas-emitidas, acesso em 06/03/2018. 
(café), Faz Rio Dourado (agora arrendam para plantio de batata), Empresa Patativa (café). Também em Taiobeiras, Lucas, Januário, Candido e Davi (todos irrigantes de café), igualmente, não possuem cadastro na ANA. (Eles podem estar captando de um afluente e não diretamente no Pardo. Isso precisa ser checado, uma vez que ainda não foi possível visitar suas propriedades).

Em toda a Bacia do Rio Pardo, portanto, tem-se que 64.804 .568 mªno são usados para irrigação, enquanto apenas $6.265 .313 \mathrm{~m} 3 /$ ano destinam-se para abastecimento público. Enfim, 60 irrigantes usam 10,3 vezes água, que os 43.507 mil domicílios, com rede de distribuição e abastecidos pelo Rio Pardo, dos dois estados, como se vê na tabela adiante. 
Tabela 3 - Outorgas Bacia do Rio Pardo, por finalidade de uso

\begin{tabular}{|c|c|c|c|c|c|c|c|c|c|c|}
\hline & Abastecimento Público & Aquicultura & $\begin{array}{l}\text { Esgotamento } \\
\text { sanitário }\end{array}$ & Indústria & Irrigação & Mineração & $\begin{array}{l}\text { Criação } \\
\text { Animal }\end{array}$ & Outro & $\begin{array}{c}\text { Volume } \\
\mathrm{m}^{3} \\
\end{array}$ & $\%$ \\
\hline BA & 5.323 .237 & $\mathbf{0}$ & 124.830 & 5.280 & 36.710 .006 & 96.000 & 109.500 & $\mathbf{0}$ & 42.368 .853 & 58,5 \\
\hline Cândido Sales & 2.501 .447 & & & & 6.706 .135 & & & & $9 \cdot 207 \cdot 582$ & 12,7 \\
\hline Encruzilhada & 302.220 & & & & 20.149 .884 & & & & 20.452 .104 & 28,3 \\
\hline Itambé & 1.109 .600 & & & 5.280 & 2.089 .890 & & & & 3.204 .770 & 4,4 \\
\hline Itapetinga & 951.161 & & & & 1.109 .288 & 19.200 & & & 2.079 .649 & 2,9 \\
\hline Itarantim & & & & & 764.244 & & & & 764.244 & 1,1 \\
\hline Macarani & & & & & 3.188 .165 & 52.800 & & & 3.240 .965 & 4,5 \\
\hline Maiquinique & & & & & & & & & 0 & 0,0 \\
\hline Mascote & $143 \cdot 752$ & & 124.830 & & & 24.000 & & & 292.582 & 0,4 \\
\hline Potiraguá & 315.057 & & & & & & & & 315.057 & 0,4 \\
\hline Ribeirão do Largo & & & & & 708.120 & & & & 708.120 & 1,0 \\
\hline Vitoria da Conquista & & & & & 1.994 .280 & & $109 \cdot 500$ & & 2.103 .780 & 2,9 \\
\hline MG & 942.076 & 668.213 & 254.653 & 0 & 28.094 .562 & 21.600 & 0 & 37.554 & 30.018 .658 & 41,5 \\
\hline Aguas Vermelhas & 452.016 & 668.213 & 254.653 & & 15.712 .600 & & & & 17.087 .482 & 23,6 \\
\hline Berizal & & & & & 1.744 .810 & & & 36.240 & 1.781 .050 & 2,5 \\
\hline Montezuma & 468.160 & & & & & & & & 468.160 & 0,6 \\
\hline Ninheira & 21.900 & & & & 7.983 .680 & & & & $8.005 \cdot 580$ & 11,1 \\
\hline Rio Pardo de Minas & & & & & 2.600 .955 & 21.600 & & 1.314 & 2.623 .869 & 3,6 \\
\hline Taiobeiras & & & & & 52.517 & & & & 52.517 & 0,1 \\
\hline TOTAL (m³/ano) & $6.265 \cdot 313$ & 668.213 & 379.483 & 5.280 & 64.804 .568 & 117.600 & 109.500 & 37.554 & 72.387 .511 & 100,0 \\
\hline$\%$ & 8,7 & 0,9 & 0,5 & 0,0 & 89,5 & 0,2 & 0,2 & 0,1 & 100,0 & \\
\hline
\end{tabular}

Fonte: Outorgas ANA 
As conclusões desta pesquisa, de modo geral, são reforçadas por outro estudo sobre o consumo de água por irrigação na bacia do rio Pardo. Em sua dissertação de mestrado, defendida na Uesb (Programa de Pós-graduação em Ciências Florestais), Lúcia C. O. Santos (2017, p. 30-32), usando metodologia e dados diferentes, que abarcam os 20 anos entre 1993 e 2013, afirma que a irrigação representa 95\% de todo o consumo de água desta bacia, registrando a maior demanda nas áreas das estações fluviométricas de Fazenda Benfica (Rio Pardo de Minas), Veredas do Paraíso (Águas Vermelhas), Cândido Sales e Inhobim (Vitória da Conquista), sabidamente, as regiões que concentram os maiores polos de irrigação da bacia. ${ }^{5}$ Este uso foi o que mais cresceu no período, seguido pelo abastecimento urbano.

Tabela 4 - Domicílios com rede geral de distribuição, rural e urbano, municípios selecionados, BA e MG, 2010

\begin{tabular}{lrrr}
\hline \multirow{2}{*}{ Município } & \multicolumn{3}{c}{ Rede geral de distribuição } \\
& Urbanos & Rurais & \multicolumn{1}{c}{ Total } \\
\hline Cândido Sales (BA) & 4.494 & 212 & 4.706 \\
Encruzilhada (BA) & 1.425 & 2.492 & 3.917 \\
Itambé (BA) & 4.938 & 39 & 4.977 \\
Itapetinga (BA) & 18.315 & 149 & 18.464 \\
Mascote (BA) & 3.183 & 110 & 3.293 \\
Potiraguá (BA) & 1.789 & 691 & 2.480 \\
\hline Total & $\mathbf{3 4 . 1 4 4}$ & $\mathbf{3 . 6 9 3}$ & $\mathbf{3 7 . 8 3 7}$ \\
\hline Águas Vermelhas (MG) & 2.423 & 593 & 3.016 \\
Montezuma (MG) & 847 & 422 & 1.269 \\
Ninheira (MG) & 760 & 625 & 1.385 \\
\hline Total & $\mathbf{4 . 0 3 0}$ & $\mathbf{1 . 6 4 0}$ & $\mathbf{5 . 6 7 0}$ \\
\hline
\end{tabular}

Fonte: IBGE - Censo Demográfico, 2010

No Mapa 1, a seguir, vê-se a concentração de outorgas a montante (acima) e a jusante (a baixo) da Barragem do Machado Mineiro, marcadas em lilás. Destaca-se que estes são dados oficiais de retirada de água. Tem-se, ainda, a montante da Barragem do Machado Mineiro, 21 mini-barramentos particulares e quatro da COPASA, três barramentos em Indaiabira/Taiobeiras e um em Berizal. De acordo com testemunhas, os barramentos não tem válvula de fundo, e três deles foram multados porque estavam aumentando seu volume de

5 SANTOS, Lucia Catherinne O. "Influência dos usos consuntivos da água e do uso e cobertura da terra na vazão da Bacia Hidrográfica do Rio Pardo". 2017, Dissertação (Mestrado), PPCF- UESB, 2017. 
forma irregular. São autorizados pela ANA, mas, ilegalmente, usam chapões para aumentar a água represada para a irrigação. ${ }^{6}$

\section{Mapa 1}

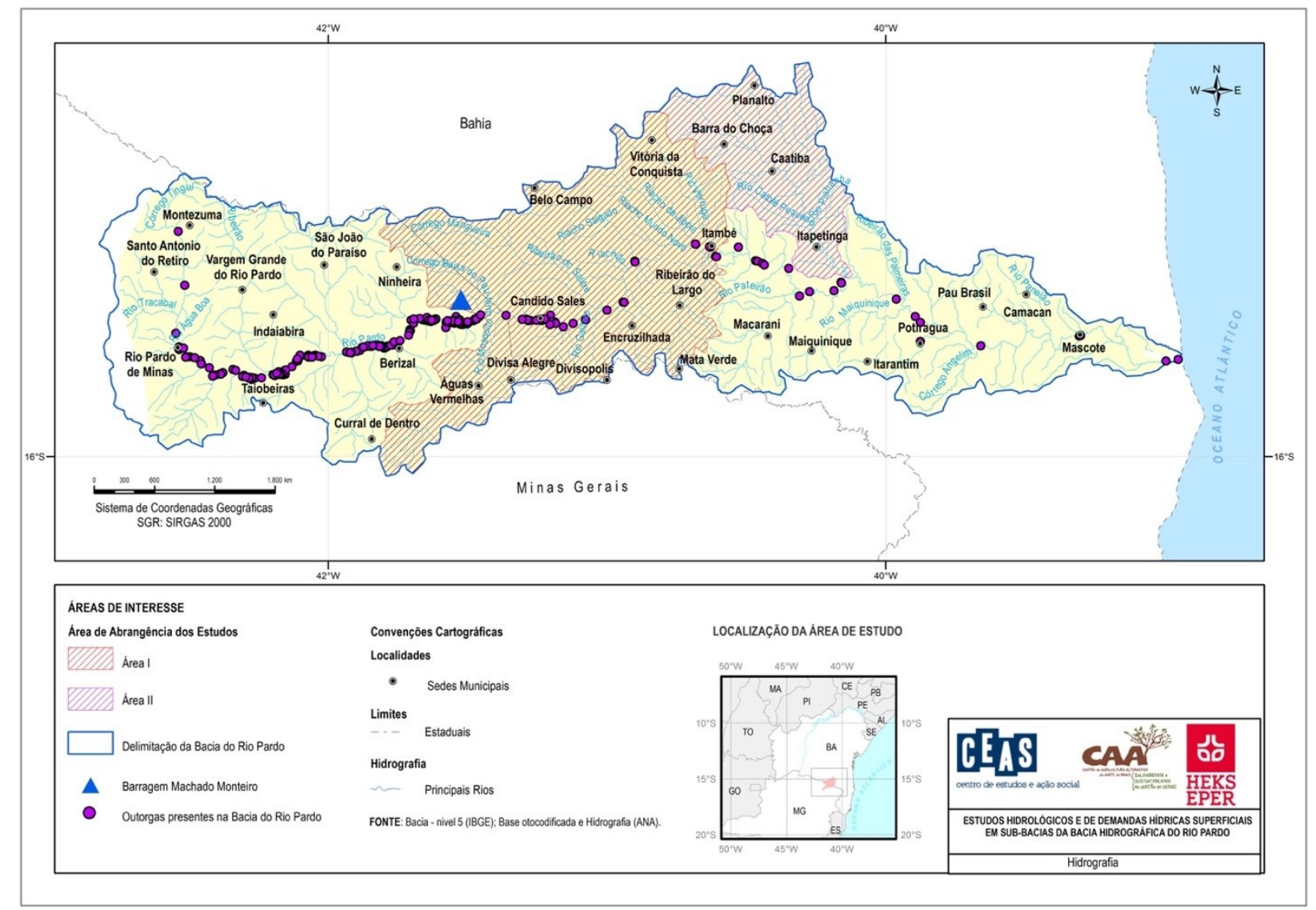

Todavia, em que pese todas as evidências acima, na percepção do senso comum, a responsabilidade da crise hídrica recai, prioritariamente, sobre as empresas de distribuição de água, EMBASA, na Bahia, e COPASA, MG. Não que elas não tenham que se redimir da falta de investimentos. Porém, a falta d'água dessas empresas na torneira mascara, junto à população, a natureza real do problema. As questões que precisam ser discutidas são: Para onde está indo a água que falta no chuveiro? Quais são as prioridades no uso da água? Por que não há gestão e controle sociais dos seus usos?

6 Infomações a partir de entrevista com Dirciano Santana, vereador de Cândido Sales e Aurindo (STRIndaiabira). 


\section{Barragens e crise hídrica}

A crise hídrica tem atingido, em especial, os municípios de Cândido Sales, Encruzilhada e Itambé. A solução apontada pela EMBASA seria a construção de três minibarragens, uma em cada município, cujo custo de elaboração do projeto é de $\mathrm{R} \$ 1,5$ milhões7. Certamente que, conforme os dados apresentados, essa solução seria pontual e não resolveria a situação no largo prazo e, muito menos, traria à tona os principais problemas envolvendo os usos da água.

Destes três municípios, Cândido Sales já tem uma proposta de construção de barragem ${ }^{8}$, cujo projeto foi financiado por um grupo de 14 irrigantes da região e apresentado à ANA, com a proposta de realização da obra, denominado Projeto Barragem Ziguarate, na propriedade de Luiz Augusto Pereira Monguilod, irrigante de Encruzilhada na divisa com Cândido Sales, que já possui 2.847.740 m³/ano em duas outorgas para gotejamento de café.

A defesa da construção de barramentos como forma de retenção e abastecimento de água para consumo humano são soluções pontuais e não atacam o problema maior de retenção de água realizado pelas grandes propriedades ao longo do Rio Pardo e em seus afluentes. Argumenta-se, ainda que, no Projeto Zigurate, terá válvula de fundo, ou seja, o fluxo do Rio será mantido de acordo com as demandas a jusante (a baixo). No entanto, as próprias demandas são subestimadas, há usos não registrados de grandes e de pequenos irrigantes e a própria possibilidade de sobrevivência do Rio precisa ser considerada. Além disso, estaria se construindo uma obra pública em uma área privada, o que beneficiaria um dos maiores irrigantes da região.

Em tempos de crise, as barragens são sempre lembradas como solução. Mas o que dizem as experiências com barragens no Rio Pardo? As barragens têm solucionado os problemas de quem, dos pequenos agricultores e da população ou dos grandes irrigantes?

A mais importante delas, a Usina Hidrelétrica do Machado Mineiro, no distrito de

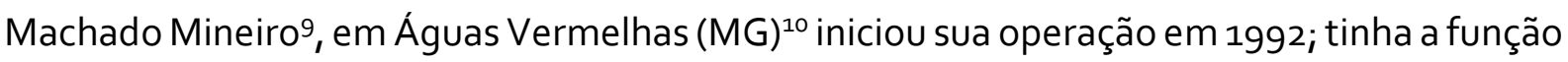

\footnotetext{
7 Entrevista Dirciano Santana

${ }^{8}$ Projeto em arquivo (pdf), disponibilizado por Dirciano Santana.

9 CEMIG. Esta barragem teve sua construção iniciada em 1989, possui $300 \mathrm{~m}$ de comprimento, altura máxima de $40 \mathrm{~m}$, com volume do reservatório de 202, 16 hm3 e potência instalada de 1,72 MW. Disponível em http://www.cemig.com.br/pt-br/a_cemig/Nossa_Historia/Paginas/Subsidiarias.aspx

${ }^{10}$ Site da CEMIG consta como localização em Ninheira.
} 
de ser geradora de energia elétrica e, principalmente, regularizar a vazão do rio. Efetivamente não gera energia e sua função, em termos de regularizar a vazão, em tempos de estiagem, é virtualmente nula, visto que o rio, nos últimos anos de crise, deixou de correr entre Cândido Sales, Encruzilhada e Itambé. Todavia, se não é eficaz para manter o rio vivo nesse trecho, e nem mesmo para o abastecimento dessas cidades, tem sido vital para o crescimento da cafeicultura irrigada, a montante e a jusante (a baixo e a cima dela).

Outra construção de barragem no rio Pardo (em Berizal) foi paralisada pelo Ministério Público, em julho de 2002, por irregularidades financeiras e ambientais e por pressão do movimento popular, que ocupou o canteiro de obras em 2000-2001. O Departamento Nacional de Obras Contra a Seca (DNOCS) queria idenizar apenas 30 famílias, impactadas pela obra, enquanto a CPT e os STRs da região contavam aproximadamente 700 famílias ${ }^{11}$. Nessa mobilização foi criado o Movimento Articulado dos Sindicatos do Alto Rio Pardo (MASTRO), formado pelos Sindicatos de Ninheira, Berizal, Santa Cruz de Salinas, Novo Horizonte, Fruta de Leite, Vargem Grande do Rio Pardo, Santo Antônio do Retiro, Montezuma, Indaiabira. ${ }^{12}$

Após a construção de Machado Mineiro, avançaram alguns fatores de risco para a segurança hídrica no vale do Rio Pardo, sobretudo as monoculturas de café e eucalipto, somando-se à pecuária extensiva nas microbacias. De acordo com dados da Pesquisa Agrícola Municipal (PAM/IBGE), a área total plantada de café, no território em questão, praticamente não se modificou, mas se deslocou. Isso fica claro, ao analisarmos individualmente os municípios, Assim, em Vitória da Conquista, onde não constam outorgas para irrigação, embora em campo se observe irrigação em Inhobim, identifica-se uma redução significativa da área plantada. Por outro lado, há taxas de crescimento elevadas em Berizal (1.232\%), Águas Vermelhas (360\%) e Ninheira (246\%), municípios grandes irrigantes localizados no Alto Rio Pardo. Além disso, estes dois últimos se destacam em termos de desmatamento no estado de Minas Gerais. ${ }^{13}$

\footnotetext{
${ }^{11}$ Entrevista Aurindo - STR de Indaiabira. O MASTRO segue até hoje articulando e apoiando estes Sindicatos e mantendo um fundo de $\mathrm{R} \$ 100 /$ mês para apoio financeiro em diversas formas de mobilização e ações.

${ }^{12}$ https://levontaiobeiras.blogspot.com.br/2012/10/barragem-de-berizal-em-nota-tecnica-do.html A execução da obra chegou a 35\% com a execução da galeria da tomada d'água e escavação e concretagem parcial do vertedouro com investimento de 26,5 milhões.

${ }^{13}$ Não há registro de área plantada em Cândido Sales, a despeito de haver outorga para irrigação em café, e também por observação de plantios em campo. Ver dados à p. 19.
} 
Tabela 5 - Área destinada à colheita de café (Ha.), municípios selecionados, BA e MG, 2000, 2006, 2010 e 2016

\begin{tabular}{llllll}
\hline Municípios & $\mathbf{2 0 0 0}$ & $\mathbf{2 0 0 6}$ & $\mathbf{2 0 1 0}$ & $\mathbf{2 0 1 6}$ & $\begin{array}{l}\text { Tx de } \\
\text { crescimento \% }\end{array}$ \\
\hline Barra do Choça (BA) & 18.430 & 23.000 & 18.000 & 19.000 & 3,09 \\
Cândido Sales (BA) & & $\ldots$ & $\ldots$ & $\ldots$ & \\
Encruzilhada (BA) & 3.500 & 5.140 & 5.000 & 5.000 & 42,86 \\
Itambé (BA) & 200 & 300 & 400 & 400 & 100,00 \\
Ribeirão do Largo (BA) & 2.500 & 2.560 & 2.500 & 2.500 & 0,00 \\
Vitória da Conquista (BA) & 14.000 & 10.000 & 10.000 & 10.000 & $-28,57$ \\
Águas Vermelhas (MG) & 100 & 195 & 170 & 460 & 360,00 \\
Berizal (MG) & 25 & 3 & 117 & 333 & $1.232,00$ \\
Indaiabira (MG) & 150 & 23 & 178 & 320 & 113,33 \\
Ninheira (MG) & 260 & 590 & 600 & 900 & 246,15 \\
Rio Pardo de Minas (MG) & 150 & 23 & 178 & 320 & 113,33 \\
Taiobeiras (MG) & 262 & 412 & 772 & 450 & 71,76 \\
\hline Total & 39.577 & 42.246 & 37.915 & 39.683 & 0,27 \\
\hline
\end{tabular}

Fonte: IBGE - Produção Agrícola Municipal

A mudança do perfil produtivo em Berizal, Ninheira e Águas Vermelhas não se deu somente pelo desmatamento e em termos de expansão de uso do solo pela cultura do café, mas também em termos de produtividade (Tabela 6), cuja explicação pode estar, justamente, na concentração dos plantios próximos à água de irrigação. Por outro lado, em todos os municípios selecionados da Bahia, houve redução da produtividade. Nesses, nota-se grande dispersão dos plantios (provavelmente, uma análise que levasse em conta somente a produtividade dos irrigantes não encontraria essa diferenca entre os dois entados da bacia, até porque sabe-se que parte dos cultivos em Minas tem proprietários baianos). De todo modo, registra-se grande diferença na produtividade do café nesses municípios mineiros, quando comparado com os municípos do outro lado da divisa, fato que se acentua em 2016.

Ranking dos estados cafeicultores (2016): Minas Gerais (1.041.541 há), Espírito Santo (425.085 há), São Paulo (199.705 há), e Bahia (163.689 ha.). Destes, só Minas Gerais (4,31\%) e, sobretudo Bahia tiveram crescimento nas áreas plantadas (21,98\%). 
Tabela 6 - Rendimento médio da produção de café, em kg/ha, municípios selecionados, Bahia e Minas Gerais 2000, 2006, 2010 e 2016

\begin{tabular}{|c|c|c|c|c|c|}
\hline Municípios & 2000 & 2006 & 2010 & 2016 & tx de crescimento (\%) \\
\hline Barra do Choça (BA) & 900 & 1140 & 900 & 1000 & 11,11 \\
\hline Cândido Sales (BA) & & & & & \\
\hline Encruzilhada (BA) & 1.200 & 780 & 600 & 490 & $-59,17$ \\
\hline Itambé (BA) & 1.200 & 600 & 600 & 468 & $-61,00$ \\
\hline Ribeirão do Largo (BA) & 900 & 600 & 600 & 470 & $-47,78$ \\
\hline Vitória da Conquista (BA) & 900 & 900 & 660 & 520 & $-42,22$ \\
\hline Águas Vermelhas (MG) & 810 & 1.461 & 752 & 3.600 & 344,44 \\
\hline Berizal (MG) & 360 & 1.666 & 717 & 3.000 & 733,33 \\
\hline Indaiabira (MG) & 1.800 & 1.782 & 2.101 & 1.859 & 3,28 \\
\hline Ninheira (MG) & 900 & 2.100 & 3.000 & 3.000 & 233,33 \\
\hline Rio Pardo de Minas (MG) & 1.800 & 1.799 & 1.440 & 2.461 & 36,72 \\
\hline Taiobeiras (MG) & 2.400 & 3.000 & 3.900 & 1.080 & $-55,00$ \\
\hline
\end{tabular}

Fonte: IBGE - Produção Agrícola Municipal

A vitalidade do café irrigado fica mais evidente qando comparamos as quantidades produzidas e suas correspondentes taxas de crescimento, em Berizal, Águas Vermelhas e Ninheira, com Vitória da Conquista, o $2^{\circ}$ maior produtor de café da região. Estes municípios produziam, em 2000, ínfimos 324 kg de café, aproximadamente $6 \%$ da produção de Vitória da Conquista, $5.400 \mathrm{~kg}$. Já no ano de 2016, eles passam a produzir $5.336 \mathrm{~kg}$, ultrapassando os $5.200 \mathrm{~kg}$ produzidos em de Vitória da Conquista (Tabela 7).

Tabela 7 - Quantidade produzida de café, em kg, municípios selecionados, Bahia e Minas Gerais, 2000, 2006, 2010 e 2016

\begin{tabular}{|c|c|c|c|c|c|}
\hline Municípios & 2000 & 2006 & 2010 & 2016 & tx de crescimento (\%) \\
\hline Barra do Choça (BA) & 13.887 & 20.976 & 16.200 & 19.000 & 36,82 \\
\hline Cândido Sales (BA) & - & $\ldots$ & $\ldots$ & $\ldots$ & \\
\hline Encruzilhada (BA) & 3.600 & 2.808 & 3.000 & 2.450 & $-31,94$ \\
\hline Itambé (BA) & 240 & 180 & 240 & 187 & $-22,08$ \\
\hline Ribeirão do Largo (BA) & 2.250 & 1.536 & 1.500 & 1.176 & $-47,73$ \\
\hline Vitória da Conquista (BA) & $5 \cdot 400$ & 7.200 & 6.600 & 5.200 & $-3,70$ \\
\hline Águas Vermelhas (MG) & 81 & 285 & 128 & 1.656 & $1.944,44$ \\
\hline Berizal (MG) & 9 & 5 & 84 & 999 & $11.000,00$ \\
\hline Indaiabira (MG) & 270 & 41 & 374 & 595 & 120,37 \\
\hline Ninheira (MG) & 234 & 1.239 & 1.800 & 2.700 & $1.053,85$ \\
\hline Rio Pardo de Minas (MG) & 666 & 1.501 & 1.633 & 1.624 & 143,84 \\
\hline Taiobeiras (MG) & 629 & 1.236 & 3.011 & 486 & $-22,73$ \\
\hline Total & 27.266 & 37.007 & 34.570 & 36.073 & 32,30 \\
\hline
\end{tabular}

Fonte: IBGE - Produção Agrícola Municipal 
Vitória da Conquista, aliás, é um dos municípios de maior área plantada na região, devido a incentivos fiscais passados, e onde se verifica uma baixa precipitação anual, implicando elevado déficit hídrico, e revelando a inviabilidade do plantio de tipo sequeiro dessa cultura na região, sobrevivendo no município, atualmente, apenas nas franjas serranas mais chuvosas e ou irrigadas. ${ }^{14}$

Uma última e conclusiva evidência do vínculo entre o crescimento da monocultura do café nas proximidades da barragem de Machado Mineiro vem do confronto dos regimes pluviométricos da região do seu entorno, com as necessidades hídricas da cafeicultura. Conforme Fernandes, A. T.; Mantovani, E. C. (2006), em estudo sobre a região Oeste da Bahia, a quantidade de água necessária para a cafeicultura irrigada é da ordem de $1600 \mathrm{~mm}$ por ano. ${ }_{15}$ Considerando-se que as chuvas em torno da barragem registram uma média inferior a 800 $\mathrm{mm} / \mathrm{ano}$, temos que as mesmas atenderiam menos de $50 \%$ da demanda da cultura. ${ }^{16}$ Assim, a quantidade de água a ser aplicada via sistema de irrigação atinge uma cifra superior a 800 $\mathrm{mm}$. Como $1 \mathrm{~mm}$ representa $1 \mathrm{l} / \mathrm{m}^{2}$ ou $10 \mathrm{~m}^{3} /$ ha, será necessário aplicar mais de $8.000 \mathrm{~m}^{3}$ por cada hectare irrigado; considerando a área plantada, indicada na PAM/IBGE (possivelmente subregistrada), de aproximadamente 40.000 hectares, seria necessário um valor superior a $320.000 .000 \mathrm{~m}^{3}$, ou seja, seriam retirados do rio do Pardo mais de 320 trilhões de litros água/ano na região em análise.

Por sua vez, dados informados pela Fazenda Olhos D'Água e Três Lagoas, em Berizal, com 360 ha irrigados, sendo 224 hectares de café e os demais com banana, milho, abóbora e feijão, o café produz 10.000 sacas/ano e consome, em sua fase adulta, $15.000 \mathrm{l} / \mathrm{ha} / \mathrm{dia} .{ }^{17} \mathrm{~A}$ matriz produtiva do café tem um uso intensivo da água como toda monocultura irrigada. $\mathrm{O}$

\footnotetext{
${ }^{14}$ Os dados relativos a Vitória da Conquista estão disponíveis em: https://www.cnpm.embrapa.br/projetos/bdclima/balanco/resultados/ba/39/balanco.html. Para Minas, ver MINAS GERAIS. "Relatório Diagnóstico Mineiros do Pardo (PA1) RP2" (2011, p. 30 - 32).

${ }^{15}$ FERNANDES, A. T.; MANTOVANI, E. C. (11/08/2006). "Como utilizar de forma racional a água e a energia na cafeicultura irrigada". Disponível em https://www.cafepoint.com.br/radares-tecnicos/irrigacao/comoutilizar-de-forma-racional-a-agua-e-a-energia-na-cafeicultura-irrigada-30447n.aspx - Sendo a região do Rio Pardo de maior evapotranspiração, se comparada ao oeste, talvez no rio Pardo a necessidade de água seja ainda maior.

${ }^{16}$ SANTOS, Op. Cit, p. 37, demonstra que a precipitação anual média nos municípios do entorno de Machado Mineiro foi de $750 \mathrm{~mm}$. Para isso usou os dados das estações pluviométricas da região, com informações que cobrem de 1993 a 2013.

${ }^{17}$ Entrevista concedida pelo gerente, em 02/03/2018. Na seca de 2015/2016, a Fazenda teria sofrido um elevado prejuízo, vez que a produção do café caiu para 500 sacas/ano.
} 
entrevistado informa que a Fazenda consome $1 \%$ do volume do lago da Barragem do Machado Mineiro e considera que, nas proximidades, há aproximadamente 2.200 ha de café irrigado, que consumiria $10 \%$ do volume do lago. Se esses números estivessem certos e considerando a existência declarada de 40 mil hectares de café irrigados, a água total demandada pela irrigação seria de 1,8 vezes o total da barragem, ou 180\%. ${ }^{18} \mathrm{O}$ absurdo dessa estimativa só reforça a necessidade de transparência na gestão e de se efetivar o controle social sobre esse bem comum, essencial à vida.

Tomando como base um consumo de 200 litros de água/habitante por dia, conclui-se que a quantidade de água gasta na irrigação do cafeeiro nesta região corresponde ao consumo de água de água de cerca de 2.191 .781 pessoas. Nem mesmo considerando todo o consumo populacional urbano e rural de todos os municípios da Bacia se chega a essa cifra, já que, de acordo com dados do Censo Demográfico do IBGE, seria cerca de um milhão de habitantes em toda a Bacia.

Assim, esse modelo altamente dependente de água irrigada mostra-se inviável e insustentável econômica e ambientalmente. Estes dados revelam a irracionalidade desse modelo de capital intensivo no campo, a exigir um volume de água muito maior que o disponível e mesmo outorgado, demonstrando que o uso irregular da água se apresenta como uma realidade para que o sistema possa funcionar.

\section{Culturas agrícolas e métodos de irrigação na Bacia do Rio Pardo}

São 10 as atividades agrícolas com registro de outorga na ANA, sendo o café (Encruzilhada, Águas Vermelhas, Berizal, Ninheira, Rio Pardo de Minas) aquele com maior volume utilizado, $\mathbf{7 2 , 1 \%}$, seguido pelo milho com 11,5\%. Destaca-se a produção de capim e pasto irrigado (Encruzilhada, Itapetinga, Itarantim, Macarani, Ribeirão do Largo), com 7,0\% e as demais culturas apresentam com percentuais menores (Tabela 9 e Gráfico 2).

\footnotetext{
${ }^{18}$ Destaca-se que, nos dados de outorgas da ANA, esta propriedade aparece com duas outorgas de água para "consumo não consuntivo", uma delas com vencimento em 13/06/2019 e outra em 23/12/2051, que seriam 35 anos de outorga. Justifica-se, mais uma vez, maior investigação sobre a captação de água desta propriedade, uma vez que ela possui barramento, captação no Rio Pardo e 360 ha hectares irrigados, conforme entrevista e observação em campo.
} 
Tabela 9 - Volume de água, m³/ano e \%, Outorgas, por Cultura Irrigada, Bacia do Rio Pardo

\begin{tabular}{lrr}
\hline Culturas & \multicolumn{2}{c}{ Volume } \\
m³/ano & $\%$ \\
\hline Café & 46.728 .818 & 72,1 \\
Milho & 7.483 .145 & 11,5 \\
Capim/Pasto & 4.541 .939 & 7,0 \\
Mamão & 4.466 .784 & 6,9 \\
Feijão & 682.067 & 1,1 \\
Maracujá & 455.744 & 0,7 \\
Abobora & 257.805 & 0,4 \\
Tomate & 140.116 & 0,2 \\
Mandioca & 33.720 & 0,1 \\
Grama & 14.430 & 0,0 \\
\hline & $\mathbf{6 4 . 8 0 4 . 5 6 8}$ & 100 \\
\hline
\end{tabular}

Gráfico 2

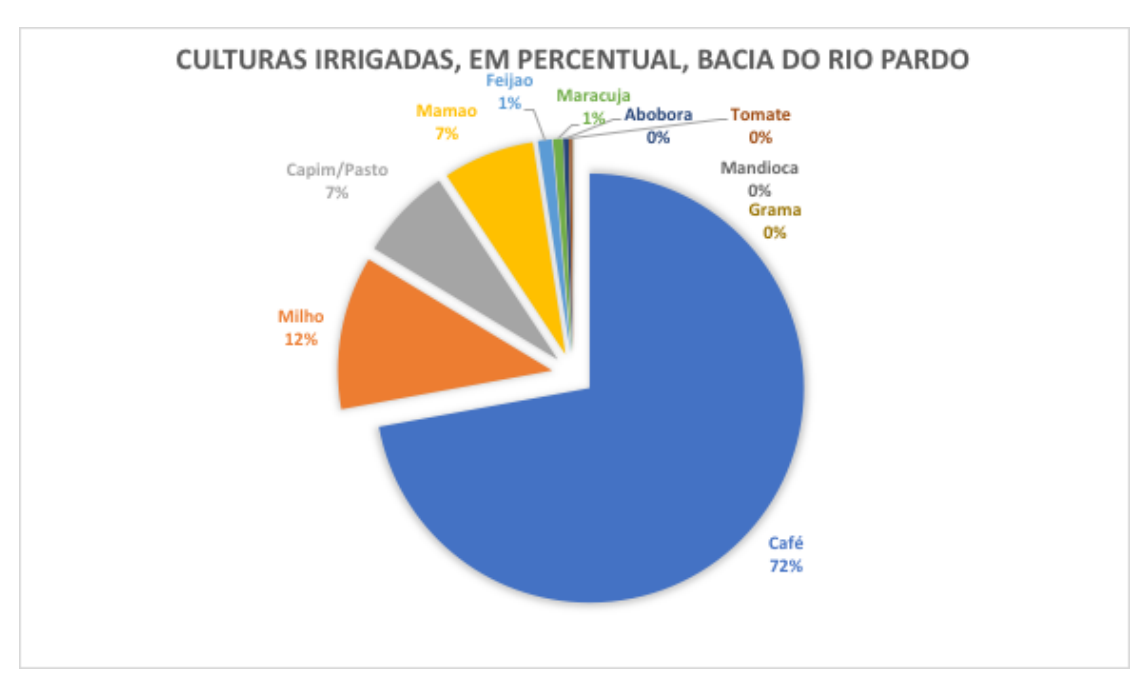

Em termos de métodos de irrigação, o gotejamento está presente na maior parte das outorgas, mas, sobretudo, encontra-se naquelas onde a demanda por água é menor. No café, onde os volumes demandados são maiores, o método mais utilizado é o pivô central. Em Encruzilhada (BA), município com maior volume outorgado de água (20.149.884 m³/ano), apenas nove irrigantes da cultura do café são responsáveis por 92\% desse consumo; os $8 \%$ restantes irrigam capim. Ressalta-se que o montante outorgado para abastecimento para o 
município foi de $302.220 \mathrm{~m} 3 / a n o$, ou seja, a irrigação capta 67,7 vezes o volume referente ao abastecimento. ${ }^{19}$

O segundo município, Águas Vermelhas (MG), tem seu volume de outorgas para irrigação entregue a quatro produtores, todos de café, são $15.712 .600 \mathrm{~m} 3 / \mathrm{ano}$. Em contrapartida, são 452.016 m³/ano para o abastecimento humano, o que corresponde a 38,7 do volume outorgado para a irrigação. Em Ninheira (MG), são somente três irrigantes, sendo que dois deles de feijão, com 1,3\% do volume outorgado, e somente um cafeicultor, o exgovernador da Bahia, Nilo Coelho, consome $7.881 .470 \mathrm{~m}^{3} / \mathrm{ano}$, o equivalente a $98,7 \%$ do total da água de irrigação desse munícipio. Sendo que o mesmo outorgante possui ainda outra outorga para irrigação de algodão, no município de Malhadas, na Bacia do Rio São Francisco, com volume de 57.676.273 m³/ano. Em uma comparação grosseira, considerando que um cidadão consome $200 \mathrm{l} / \mathrm{dia}$, em suas necessidades diárias, este produtor tem em seu benefício para uso produtivo $179.610,2 \mathrm{~m} 3 / \mathrm{dia}$, ou $179.610 .200 \mathrm{l} / \mathrm{dia}$. A outorga para abastecimento humano, em Ninheira, foi de 21.900 mªno, e o volume para irrigação foi 365,5 vezes maior, de $7.983 .680 \mathrm{~m}^{3} / \mathrm{ano}$.

Em Cândido Sales (BA, são 9.207.582 m³/ano em volume de outorgas, sendo que, para irrigação, são 6.706.135 e, somente uma propriedade consome $66,6 \%$ do total, ou seja, 4.466.784 m³/ano para o cultivo de mamão, quase o dobro do montante outorgado para abastecimento de todos os domicílios do município, com rede de abastecimento, que é de 2.501.447 m³/ano. Outras três propriedades de café, milho e feijão, são consumidoras dos demais $33,4 \% .^{20}$

Destaca-se que as outorgas aqui tratadas são somente do leito do Rio Pardo que, por cruzar dois Estados, são registrados pela ANA. Os dados referentes aos seus afluentes, que, certamente, influenciam na manutenção do próprio Rio Pardo, não estão sendo aqui tratados.

A predominância na irrigação pelo insustentável método do pivô central pode ser melhor visualizada graficamente, abaixo.

\footnotetext{
19 IBGE - Produção Agrícola Municipal (PAM)

20 Todos os dados municipais são da PAM/IBGE. Há uma outorga para gotejamento de café, de 1.291.651 m³/ano, em 2014, para Cândido Sales, mas nos dados de 2016, não consta nem um hectare de área plantada de café.
} 


\section{Gráfico 3}

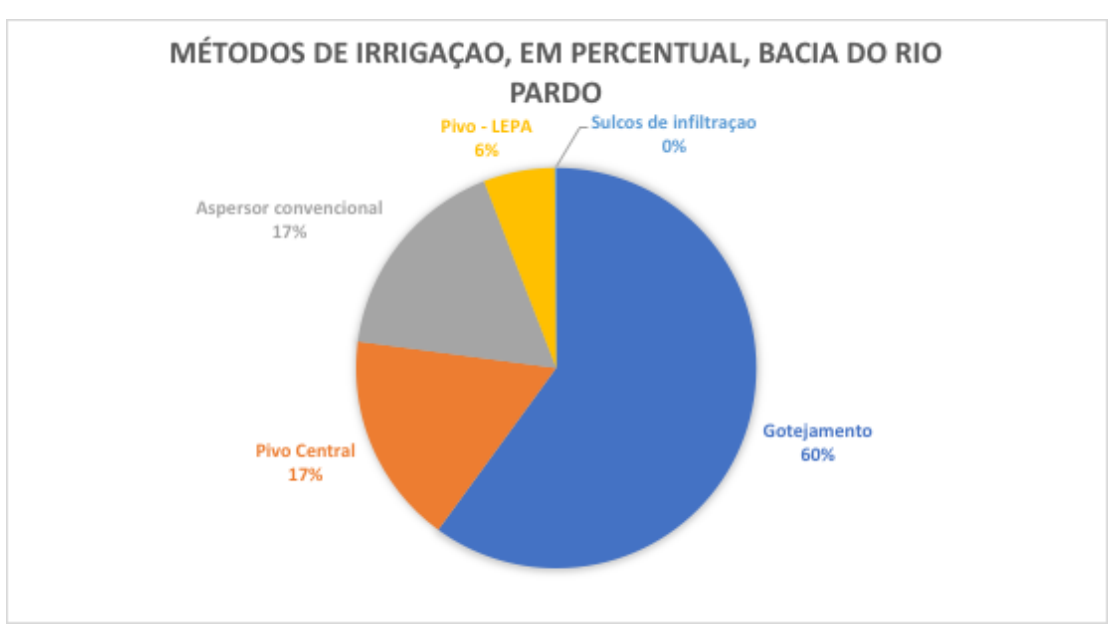

Outra cultura importante na bacia do rio Pardo é a de eucaliptos. Com relação a esse plantio, nos últimos anos, constata-se decréscimo de área plantada na região, a exceção de Encruzilhada e Berizal (Tabela 10). Todavia, deve-se registrar que os dados oficiais declarados parecem ser muito inferiores ao que, de fato, se observa na região. Por essa razão, a pesquisa sobre os impactos dessa monocultura na disponibilidade de água na bacia do rio Pardo deve ser aprofundada com a utilização de outras fontes e metodologias.

Tabela 10 - Área total plantada de eucalipto, em ha, municípios selecionados, Bahia e Minas Gerais, 2014, 2015 e 2016

\begin{tabular}{lrrrr}
\hline Municipios & & & \multicolumn{2}{c}{ taxa de } \\
\hline Barra do Choça (BA) & $\mathbf{2 0 1 4}$ & $\mathbf{2 0 1 5}$ & $\mathbf{2 0 1 6}$ & crescimento \\
Cândido Sales (BA) & 5.000 & 5.000 & 901 & $-81,98$ \\
Encruzilhada (BA) & 9.800 & 9.800 & 4.343 & $-55,68$ \\
Ribeirão do Largo (BA) & 10.000 & 10.000 & 11.706 & 17,06 \\
Vitória da Conquista (BA) & 400 & 400 & 394 & $-1,50$ \\
Águas Vermelhas (MG) & 35.000 & 35.000 & 10.384 & $-70,33$ \\
Berizal (MG) & 8.897 & 8.497 & 8.709 & $-2,11$ \\
Indaiabira (MG) & 1.310 & 2.300 & 2.000 & 52,67 \\
Ninheira (MG) & 9.600 & 10.000 & 10.000 & 4,17 \\
Rio Pardo de Minas (MG) & 6.622 & 6.400 & 6.200 & $-6,37$ \\
Taiobeiras (MG) & 12.793 & 21.000 & 21.000 & 64,15 \\
\hline Total & 22.140 & 22.500 & 22.750 & 2,76 \\
\hline
\end{tabular}

Fonte: IBGE - Produção da Extração Vegetal e da Silvicultura

O setor vem enfrentando retrações em função da crise econômica nacional, visto que a produção regional destina-se ao mercado interno, siderúrgicas em Minas Gerais e usos 
diversos internos. No entanto, não se pode considerar que essa cultura está sendo substituída na região. Mas, certamente, o ímpeto dos plantios da primeira década deste século não existe mais. Destaca-se, também, que a redução das áreas plantadas em Berizal e Indaiabira advém do vencimento dos contratos de 20 anos de uso das terras públicas, que agora são disputadas pelos agricultores do norte mineiro. ${ }^{21}$

Nesta direção de proteção e disputa pelos recursos do território, também devem ser citadas as iniciativas dos movimentos e entidades sociais do sudoeste baiano, que fizeram aprovar leis de restrição à expansão dessa monocultura em 5 municípios (Barra do Choça, Piripá, Cordeiros, Maiquinique e Itarantim), e fazem tramitar projeto com o mesmo objetivo em Encruzilhada, onde enfrentam a oposição dos governantes locais. Essas Leis de Iniciativa Popular promoveram amplo debate na sociedade local, em geral, sendo subscritas por cerca de 10 dos eleitores municipais, em alguns casos, como Maiquinique e Itarantim, ganhando a opinião pública contra essa monocultura. ${ }^{22}$

\section{Conclusões preliminares}

A bacia do rio Pardo parece necessitar de urgente reconfiguração. Nessa bacia, o problema é socioeconômico, ambiental e envolve mais de um milhão de habitantes. Portanto, não é aceitável que 60 irrigantes possam decidir e, em contexto de crise ambiental e hídrica, deliberar, com a anuência do órgão regulador, as prioridades de uso da água, muitas vezes, deixando sem fluxo permanente boa parte da calha do rio, obrigando as populações urbanas de suas margens a ter que encontrar outras fontes de abastecimento.

Concretamente, o capital no campo adotou as águas do rio Pardo, represadas na barragem de Machado Mineiro, como um insumo ambiental essencial para a sua reprodução ampliada. Há evidências de que, para as margens dessa represa e para suas proximidades, se deslocaram os cultivos intensivos de algumas culturas, notadamente o café, que nelas tem crescido a taxas exponenciais, enquanto, ao mesmo tempo, regridem os plantios de sequeiro.

\footnotetext{
${ }^{21}$ Entrevista Laurindo STR/Indaiabira.

${ }^{22}$ ANDRADE, M. L. A monocultura do eucalipto: conflitos socioambientais, resistências e enfrentamentos na região do sudoeste baiano. https://repositorio.ufba.br/ri/handle/ri/20649
} 
Todavia, esse modelo de agricultura, baseado principalmente no pivô central, altamente dependente de água irrigada, mostra-se insustentável socioambientalmente, afinal, exige um volume de água muito maior que o disponível legalmente para seu uso, chegando a burlar, por meio de expedientes irregulares, o volume outorgado pela Agência Nacional de Águas. Assim, temos que o uso irregular da água se constitui como uma base para o funcionamento do sistema irrigante e, seguramente, constitui-se em uma das causa essenciais da crise de abastecimento que se abateu em alguns municípios da bacia, entre 2015 e 2017.

\section{Dados dos autores}

Joaci de Sousa Cunha

Advogado, assessor do Ceas, co-editor dos Cadernos do Ceas e Pós-doutorando no Programa de Políticas Sociais e Cidadania da Universidade Católica do Salvador (PPGPSC-UCSal), onde discute os conflitos agrários e socioambientais na bacia do Rio Pardo nos Estados da Bahia e Minas Gerais. Email: joacisc@gmail.com

Gilca Garcia de Oliveira

Professora da Universidade Federal da Bahia, onde leciona as disciplina Desenvolvimento Socioeconômico, Teorias do Desenvolvimento, Desenvolvimento Comparado e Economia Rural. Atua no projeto Geografar e nos Programas de Pós-Graduação em Economia (PPGE/UFBA) e em Geografia (POSGEO/UFBA). E-mail: gilca.oliveira@gmail.com

Maicon Leopoldino de Andrade

Agrônomo, e mestre em Geografia Agrária pela UFBA, assessor do Ceas e pesquisador vinculado ao Projeto Geografar. Email: mleopoldinodeandrade@gmail.com 